\section{Salt Excretion in Marine Birds}

MAY I add a further observation to F. S. Russell's interesting communication under this title ${ }^{1}$ ? More than thirty years ago I noticed a similar thing in the giant petrel or stinker (Macronectes giganteus) of the southern oceans, and published ${ }^{2}$ an account of it, though not in a scientific paper, in 1951: "When [a flying stinker] is right alongside and you can seo him plainly, nearly always you will notice that he has a drop on his nose; hanging from the tip of the hook at the end of his beak is a drop of somethingwhether water or some other fluid I know not". This, too, was evidently salt excretion in action.

Zoological Society of London,

\section{HaRRISON MatThEWS}

Regent's Park,

London, N.W.1.

'Russell, F. S., Nature, 182, 1755 (1958).

${ }^{2}$ Matthews, L. Harrison, "Wanderiag Albatross" (MacGibbon and Kee, London, 1951).

\section{PSYCHOLOGY}

\section{Colour Vision Phenomenon of a New Class}

IF one looks toward a bright field of white light (white cloud or white fluorescent lamp), interposes an orange Wratten No. 21 filter for 5 sec., then removes the filter, a bright, saturated greenish-yellow pattern is seen. It is of irregular, blotchy shape and persists for $1-2$ sec.

The hue and saturation of the pattern remain unchanged despite wide variation in choice of filter used in step 1. (Step 1 is the 5-sec. period in which an orange filter or the equivalent is used; step 2 is the 1-2-sec. period in which the pattern is seen.) Instead of the orange Wratten 21 filter, any filter that transmits much 540-590 mu light and no light of wave-length below $490 \mathrm{~m} \mu$ may be used.

In step 2, instead of using no filter, any blue, green, yellow, orange, purple or grey filter that has appreciable transmittance near $470 \mathrm{~m} \mu$ may be interposed.

To predict whether a filter will succeed in step 1 , the spectral transmittance curve of the filter must be examined. The colour of the filter may not be in. dicative. (I have a pair of orange filters that are almost identical in colour but behave oppositely, one succeeding in step 1 and the other in step 2.)

Moderately high intensity is required in step 1. The intensity of a white cloud or a bare white fluorescent lamp is very satisfactory. A heavily overeast sky, or a shest of white paper resting on the top of a desk, may be too dim.

The intensity and quality of the step 1 illumination determine whether the pattern will be seen (in the subsequent step), but do not govern the brightness or colour of the pattern.

It is the step 2 illumination that governs the brightness and colour of the pattern. If the step 2 illumination consists of white light, the pattern appears greenish-yellow, and the brightness is roughly proportional to the intensity of the white light. If the step 2 illumination consists of just 400-500 mu light, the pattern appears green. If the step 2 illumination contains $400-500 \mathrm{~m} \mu$ light and also light in longer wave-length bands, the hue appears intermediate between green and the hue one normally associates with the longer wave-length bands. For example, the illumination obtained with the aid of a white fluorescent lamp and a reddish-purple filter transmitting in the two bands $400-500 \mathrm{m \mu}$ and 600 $700 \mathrm{~m} \mu$ leads to a pattern that is midway between green and red, namely, orange.

If the step 2 illumination is of zero intensity, the pattern does not appear. (Various after-images appear, but seem unrelated to the pattern under discussion.)

The pattern has an irregular, blotchy shape, and very different shapes may be noticed in successive trials. The size of the pattern may decrease markedly from one trial to the next, and, after four or five trials made within a period of one minute, the pattern may entirely fail to appear. In the first trial the pattern may have an angular width of 40-80 deg., and the fovea and macula regions may participate; in subsequent trials the pattern becomes less extensive, and the fovea and macula regions may fail to participate. The grain size, or resolution, of the pattern is low, being perhaps $0 \cdot 1-0.5 \mathrm{deg}$.

After resting his eye for $10 \mathrm{~min}$. the observer may see the phenomenon again. Resting dees not require dim light or darkness; it requires merely the avoidance of light that is devoid of energy in the 400-500 mu range. Looking through any step I filter is tiring, but looking through any step 2 filter is not. Thus tiring, too, depends on the transmittance curve of the filter rather than on its colour.

In the first trial (that is, when the eye is fresh), the duration of step 1 may be reduced; the 5-sec. duration is not necessary, and durations as short as 2 sec. (sometimes even $\frac{1}{2}$ sec.) suffice. Moreover, the intensity of the pattern afterwards seen is independent of the step 1 duration.

When the pattern disappears (after 1-2 sec. of step 2 illumination), it does not fade gradually and uniformly, but disappears piecemeal, each piece disappearing suddenly.

Each eye acts independently. One eye may become tired and the other (not exposed to step 1 illumina. tion) may remain fresh. Indeed, the different regions of a single eye appear to act independently. Accordingly, split-field experiments are feasible. For example, in step 2 the patterns produced by two unlike filters held side-by-side a few inches in front of the eye may be compared.

A blue or magenta pattern is sometimes observed in step 1 if this step is prolonged for 5-15 sec., and this pattern sometimes has a shape similar to that of the pattern afterwards appearing in step 2. (I am indebted to my colleague E.S. Emerson for pointing this out.)

Approximately fifty of my friends have tried to see the greenish-yellow pattern by the method indicated in the first paragraph, and more than forty succeeded.

The new phenomenon has little in common with the usual adaptation, fatigue, or complementarity phenomena. Such phenomena usually involve smooth fields, dim and unsaturated colour, slow build-up and gradual fading. Also, the hues perceived usually change when the hues of any of the exciting fields are changed, and they are similar when exciting fields are similar in colour. The new phenomenon exhibits very different tendencies which are suggestive of abrupt switching mechanisms.

\section{WILlTaM A. SHORCLIFY}

Research Laboratory,

Polaroid Corporation,

Cambridge, Mass. Oct. 21. 